\title{
Heresy of immanence
}

John Maddox

The Probability of God. By Hugh Montefiore.

SCM Press, 26-30 Tottenham Road, London: 1985. Pbk £6.95.

ON MATTERS of dogma the Anglican Church has an almost Unitarian god-ofyour-choice flexibility, typified by the vicar in the 1960s revue "Beyond the Fringe" who was indistinguishable from a social worker and whose slogan was "Call me Bill; that's the kind of vicar I am"'. Hugh Montefiore, Anglican Bishop of Birmingham since 1978 , is that kind of bishop.

The Probability of God is only marginally a theological work which, in that respect, has much in common with the opinions of the turbulent northern bishops such as the new incumbent at Durham, who is forever shocking the popular newspapers by saying that he doubts the doctrine of trans-substantiation. The real purpose of the book is to demonstrate the immanence of God (or, more ecumenically, I suppose, some God) from the explanatory incompleteness of scientific theories, from cosmology to evolution.

To be frank (and fair), the book is a good and even entertaining read. Over the past few years, Montefiore has taken a serious and continuing public interest in matters such as the environment and arms control. He is both reasonable and earnest, willing to acknowledge that he does not know science at first hand, insistent nevertheless that it must be possible for an honest enquirer to get to the bottom of it (in which he is right) and, then, willing to take up the cudgels in the defence of what seems sanity. If there have to be bishops, nobody could ask for better.

The book is as reasonable as the man. On cosmology, for example, Montefiore does not seize on the big bang as proof that there is (or at least was) a Creator; that, he says, would be "to confuse secondary with primary causes". Instead, he follows the recent writings of Professor Paul C. Davies in emphasizing the numerical coincidences without which life as we know it would not have been possible - the small but not-too-small degree of anisotropy at the beginning that made it possible for galaxies to form; the particular ratio of gravitational and electromagnetic forces which ensures that all stars are not red dwarfs; the particular value of the coupling constant of the strong nuclear force which means that heavy elements (which we need in our enzymes) are stable but which is not so great that the post-big-bang ratio of hydrogen to helium would have been negligible.

Montefiore's refrain is typified by the declaration that "It seems remarkable that the possibility of a planet where life as we know it could evolve should depend upon the precise value of this, the weak nuclear coupling constant'". The anthropic principle, which has it that people can observe only a universe conducive to their own existence, is dismissed, but unconvincingly. Lovelock's Gaia hypothesis is a natural next: if the temperature on the surface of the Earth has been that which has been suitable for the survival of living things since the Precambrian, the ups and downs of the solar constant, or the variations of the chemical composition of the atmosphere notwithstanding, does it not follow that there must have been some intervention on behalf of us and our kind?

The texture of the two evolutionary chapters is different, even though Montefiore again begins by not taking the easy way out by letting everything hang on the belief that there has been too little time since the beginning of the Solar System for such a complicated set of living species as are now extant to have evolved. Montefiore argues instead from particular examples, but first asserts that science has made a dogma of natural selection. The rest is a collection of gee-whizz stories, "puzzle after puzzle". Why are our viscera the way they are? Why should Drosophila larvae be interposed between egg and adult? Why several independent and apparently successful attempts to evolve an eye? Popper's description of Darwinism as metaphysical (because it cannot be falsified) is mentioned, Popper's recantation is not.

In passing, Montefiore roundly castigates the Creationists, condemns Lysenko, concludes regretfully that there is no hope for Christians in Lamarck but plainly has a soft spot for $\mathrm{Dr}$ Ted Steele, the immunologist who caused a minor sensation a few years ago by claiming that immunological genetic changes may be inherited in the germ line. Mystifyingly, he also pats Rupert Sheldrake on the back, noting that the tendency for living cells to assemble in ordered ways can be explained if, indeed, there are "morphogenetic fields" which, for example, guide neurones to the connections with others that make them function properly.

Montefiore's God, therefore, is not a once and for all God, one who drew up the laws of physics and then left us to it, nor a "God of the gaps", one who may have intervened from time to time, but is instead an immanent God, embedded in the Universe and helping to make it tick from one instant to the next. By means of an argument reminiscent of Arthur Koestler's Roots of Coincidence, a tract in favour of the paranormal, Montefiore concludes that ○1985 Nature Publishing Group the nature of the Universe makes the hypothesis of God probable, whereupon more familiar religious arguments lead to Christianity and all that. In passing (and at the outset), he rejects the notion that religion is a code by which people may distinguish ethical and moral behaviour from other kinds of behaviour, and which is therefore orthogonal to rational consideration of the Universe.

Although the cosmological part of Montefiore's argument would fall apart if the ambitions of particle physicists to unify the four forces of nature were to succeed, and demonstrate that the cosmic coincidences can be derived from the laws of physics, the flaw in the whole argument is not in the detail but in the grand design. Montefiore writes as if present scientific understanding of the Universe were complete, as if we shall always be stuck, for example, with the model of the big bang (in its contemporary form, no older than the discovery of the microwave background radiation). It would be an interesting exercise if somebody were to rewrite Montefiore's book at intervals of, say, five years; his natural theology (pace David Hume) would repeatedly be found to derive from different sets of circumstances.

Indeed, Montefiore's whole enterprise is more hazardous, and dangerous, than his reasonable tone implies. His immanent God, working in everything, qualifies him as a pantheist. One does not have to go quite as far as Hermann Bondi, whom Montefiore quotes as having described religion as a "dangerous and habit-forming evil", to be deeply suspicious of how pantheism could corrupt the process of scientific enquiry. At what point in the investigation of the evolution of the human eye, for example, will investigators feel free to chicken out, ascribing some parts of the process to natural selection and others to God? Montefiore says his is not the "God of the gaps", but it sounds a bit like the God of the unsolved problems.

Religious belief is common, even among scientists, and, in moderation, is at worst harmless. Many believers are content with what seems to them the sensible position that religious belief is neither dependent on nor even connected with the character of the Universe in which they live and carry out experiments. Others take the view that physical divine intervention ended with the big bang. Explanations of the real world that suppose there is an invisible hand somewhere, making sure that hidden purposes are fulfilled even in the face of the laws of physics are less common but, in their nature, more challenging. Montefiore's book, although honest to the point of saying that "the possibility that there is no God remains open" (but is "wildly improbable'), asks of its readers a concession to irrationality that most will find impossible to make.

John Maddox is Editor of Nature. 